\title{
Elevation in High-Sensitivity Troponin $T$ in Heart Failure and Preserved Ejection Fraction and Influence of Treatment With the Angiotensin Receptor Neprilysin Inhibitor LCZ696
}

\author{
Pardeep S. Jhund, MBChB, PhD; Brian L. Claggett, PhD; Adriaan A. Voors, MD; \\ Michael R. Zile, MD; Milton Packer, MD; Burkert M. Pieske, MD; \\ Elisabeth Kraigher-Krainer, MD; Amil M. Shah, MD; Margaret F. Prescott, PhD; \\ Victor Shi, MD; Marty Lefkowitz, MD; John J.V. McMurray, MD; Scott D. Solomon, MD; \\ for the PARAMOUNT Investigators*
}

\begin{abstract}
Background-Elevated high-sensitivity troponin is associated with increasing disease severity in patients with stable heart failure with reduced ejection fraction, but less is known about the association in heart failure with preserved ejection fraction.

Methods and Results - We examined the prevalence of elevated high-sensitivity troponin T (hs-TnT) in 298 patients with heart failure with preserved ejection fraction enrolled in the Prospective comparison of angiotensin receptor neprilysin inhibitor with angiotensin receptor blocker on Management Of heart failUre with preserved ejectioN fracTion (PARAMOUNT) trial, in which the angiotensin receptor neprilysin inhibitor LCZ696 reduced markers of heart failure severity compared with valsartan. We assessed the association between hs-TnT and cardiac structure and function, and the effect of LCZ696, compared with valsartan, on hs-TnT over 36 weeks. Elevated hs-TnT in the myocardial injury range $(>0.014 \mu \mathrm{g} / \mathrm{L})$ was found in $55 \%$ of patients and was associated with older age, history of diabetes mellitus, higher N-terminal pro-brain natriuretic peptide, lower estimated glomerular filtration rate, and larger left atrial size, left ventricular volume, and mass. LCZ696 treatment reduced hs-TnT to a greater extent at 12 weeks (12\% reduction; $P=0.05$ ) and at 36 weeks ( $14 \%$ reduction; $P=0.03$ ) compared with valsartan.

Conclusions - Troponin $\mathrm{T}$ was elevated in a substantial number of patients enrolled in a heart failure with preserved ejection fraction clinical trial and was associated with abnormalities of cardiac structure, function, and elevated baseline N-terminal pro-brain natriuretic peptide. Decreases in hs-TnT with LCZ696 in parallel with improvement in N-terminal pro-brain natriuretic peptide and left atrial size suggest that the angiotensin receptor neprilysin inhibitor LCZ696 may reduce this measure of myocardial injury in heart failure with preserved ejection fraction.
\end{abstract}

Clinical Trial Registration-URL: http://www.clinicaltrials.gov. Unique identifier: NCT00887588.

(Circ Heart Fail. 2014;7:953-959.)

\section{Key Words: heart failure $\boldsymbol{\square}$ neprilysin $\boldsymbol{\square}$ troponin $\mathrm{T}$}

$M^{s}$ yocardial damage is one of the central pathophysiological processes in heart failure with reduced ejection fraction (HFrEF). Ongoing myocardial damage detected with standard and high-sensitivity troponin assays ${ }^{1-4}$ has been demonstrated during acute decompensation and in stable outpatients with $\mathrm{HF}^{3}$ Higher detectable troponin concentrations have been associated with abnormalities of cardiac structure and function ${ }^{5,6}$ and poorer prognosis in HFrEF. ${ }^{7}$ Heart

Clinical Perspective on p 959

Received May 2, 2014; accepted September 22, 2014.

From the Cardiovascular Division, Brigham and Women's Hospital, Boston, MA (P.S.J., B.L.C., A.M.S., S.D.S.); BHF Glasgow Cardiovascular Research Centre, Institute of Cardiovascular and Medical Sciences, University of Glasgow, Glasgow, United Kingdom (P.S.J., J.J.V.M.); Department of Cardiology, University Medical Center Groningen, University of Groningen, Groningen, The Netherlands (A.A.V.); Ralph H. Johnson Veterans Affairs Medical Center, Charleston, SC (M.R.Z.); Medical University of South Carolina, Charleston (M.R.Z.); Department of Clinical Sciences, University of Texas Southwestern Medical Center, Dallas (M.P.); Department of Cardiology, Medical University Graz, Graz, Austria (B.M.P., E.K.-K.); and Novartis Pharmaceuticals, East Hanover, NJ (M.F.P., V.S., M.L.).

*A list of all PARAMOUNT Investigators is given in the Data Supplement.

Guest Editor for this article was Biykem Bozkurt, MD, PhD.

The Data Supplement is available at http://circheartfailure.ahajournals.org/lookup/suppl/doi:10.1161/CIRCHEARTFAILURE.114.001427/-/DC1. Correspondence to Scott D. Solomon, MD, Cardiovascular Division, Brigham and Women's Hospital, Boston, MA 02115. E-mail ssolomon@ rics.bwh. harvard.edu

(C) 2014 American Heart Association, Inc.

Circ Heart Fail is available at http://circheartfailure.ahajournals.org 
failure with preserved ejection fraction (HFpEF) accounts for up to $50 \%$ of cases of heart failure. While elevated troponin has been detected in hospitalized patients with HFpEF, ${ }^{8-10}$ whether troponin is detectable in stable outpatients with HFpEF, and whether elevations in troponin are related to abnormalities of cardiac structure and function, is unknown. ${ }^{10-13}$

The Prospective comparison of angiotensin receptor neprilysin inhibitor with angiotensin receptor blocker on Management Of heart failUre with preserved ejectioN fracTion (PARAMOUNT) trial was a phase II trial testing the safety and efficacy of LCZ696 in stable outpatients with HFpEF. PARAMOUNT demonstrated that LCZ696 reduced N-terminal pro-brain natriuretic peptide (NT-proBNP) at 12 weeks and left atrial size and New York Heart Association (NYHA) class at 36 weeks. ${ }^{14}$ We examined the prevalence and correlates of biochemical evidence of myocardial damage, detected using high-sensitivity troponin- $\mathrm{T}$ (hs-TnT), and whether therapy with LCZ696 affected hs-TnT in patients with HFpEF.

\section{Methods}

The design and results of the PARAMOUNT trial (registered at ClinicalTrials.gov, NCT00887588) have been previously published. ${ }^{14}$ PARAMOUNT was a randomized, double-blind, parallel-group, active-controlled trial. Men and women aged $\geq 40$ years with a left ventricular ejection fraction $\geq 45 \%$ and with a documented history of heart failure with associated signs or symptoms were eligible for randomization. Patients were required to have a NT-proBNP level of $\geq 400 \mathrm{pg} / \mathrm{mL}$ at screening, be on diuretic therapy, and have a systolic blood pressure $\leq 140 \mathrm{~mm} \mathrm{Hg}$, or $\leq 160 \mathrm{~mm} \mathrm{Hg}$ if on 3 or more blood pressure drugs at randomization, have an estimated glomerular filtration rate (eGFR) $\geq 30 \mathrm{~mL} / \mathrm{min}$ per $1.73 \mathrm{~m}^{2}$ at screening, and a potassium concentration $\leq 5.2 \mathrm{mmol} / \mathrm{L}$. Treatment assignment was stratified by previous use of angiotensin-converting enzyme inhibitor or angiotensin receptor blocker and region. The primary end point was change in NT-proBNP from baseline to 12 weeks. The study protocol was approved by all individual site institutional review boards and ethics committees, and all recruited patients gave written informed consent.

NT-proBNP was measured at screening, randomization, week 4, week 12, and week 36 or at an earlier end of study visit if premature termination. NT-proBNP was measured at a central laboratory (Quest Diagnostics, Valencia, CA) with the Elecsys NT-proBNP immunoassay (Roche Diagnostics, Indianapolis, IN). Samples were taken for hs-TnT at randomization, 12 weeks and 36 weeks. Plasma hs-TnT was measured using the high-sensitivity Roche Elecsys assay (lot number 167345; Roche Diagnostics GmbH, Mannheim, Germany) at a central laboratory (Clinical Reference Laboratory-Europe Ltd, UK). The between-run variation of hs-TnT levels below the limit of quantification $(0.013 \mu \mathrm{g} / \mathrm{L})$ was not sufficiently high to permit analysis of the actual values. However, as a sensitivity analysis, we imputed a value of half the lower limit of quantification, as has been performed previously with this assay, ${ }^{15}$ and imputed a value near to the limit of quantification $(0.012 \mu \mathrm{g} / \mathrm{L})$ to limit any bias from imputing a value too far from the lowest measured value. All samples were stored at $-80^{\circ} \mathrm{C}$ and analyzed in a batch. There was no difference between treatment groups in the duration of storage $(P=0.70)$. A hs-TnT sample was available for 298 patients. Echocardiography was performed at screening, randomization, week 12, and week 36 or at end of study or early termination visits. Analyses were conducted at a core laboratory (Brigham and Women's Hospital, Boston, MA). Measurements were made in triplicate in accordance with the recommendations of the American Society of Echocardiography. ${ }^{16}$ Myocardial strain was analyzed, as previously described. ${ }^{13}$

\section{Statistical Analysis}

For patients with a hs-TnT value below the lower limit of quantification $(<0.013 \mu \mathrm{g} / \mathrm{L})$, we imputed half the lower limit of quantification. ${ }^{15}$

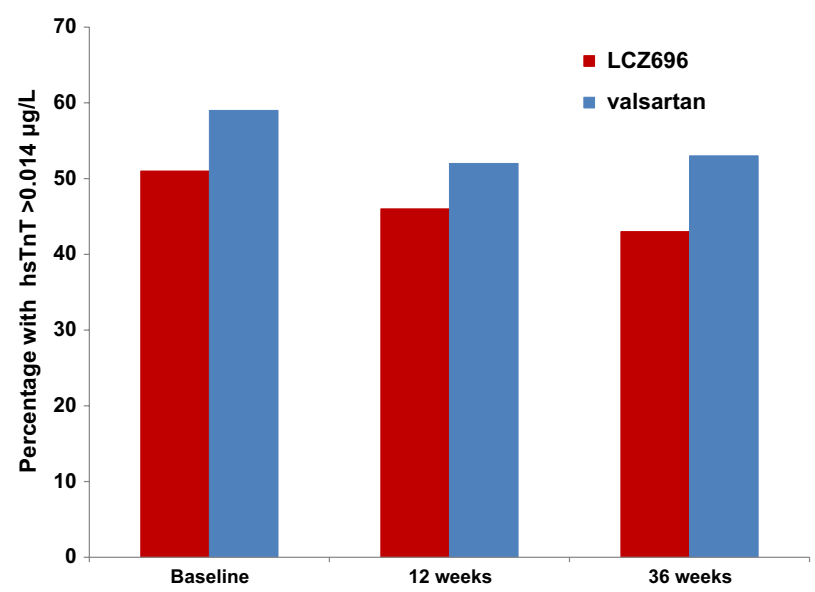

Figure 1. High-sensitivity troponin T (hs-TnT) levels in the myocardial injury range. Proportion of individuals with a hs$\mathrm{TnT}>0.014 \mu \mathrm{g} / \mathrm{L}$ at baseline, 12 weeks and 36 weeks according to treatment group.

Correlation between hs-TnT and $\operatorname{logNT}$-proBNP was assessed using the Spearman correlation. Associations between categories of hs-TnT and baseline variables were examined using $t$ tests and $\chi^{2}$ tests where appropriate, with the exception of NT-proBNP, which was tested using the Wilcoxon rank-sum test due to skewness, and NYHA class, which used the Fisher exact test. Associations between baseline variables and categories of change in hs-TnT from baseline to 36 weeks (decrease, no change, or increase) were conducted via trend test across change categories. NT-proBNP was assessed using the Cuzick nonparametric trend test. The end point of change in hsTnT was analyzed using multiple linear regression with postbaseline log-transformed hs-TnT as the outcome, randomized treatment and the stratification variables (previous use of an angiotensin-converting enzyme inhibitor or angiotensin receptor blocker, and region) as fixed factors, and the baseline log-transformed hs-TnT as a covariate. The distribution of hs-TnT was skewed (mean [SD] 0.0198 [0.0168] and median $[\mathrm{IQR}]=0.015[0.0065-0.027])$; therefore, the values were log transformed. We examined the end point of change in hs-TnT using a binary outcome of hs-TnT $>0.014 \mu \mathrm{g} / \mathrm{L}$ and hs-TnT $\leq 0.014 \mu \mathrm{g} / \mathrm{L}$, ie, within or above the 99th centile of the general population and the cutoff used to define myocardial injury, using logistic regression adjusting for the variables above. As sensitivity analyses, we used linear regression models in which an alternate value $(0.012)$ was imputed for those below the lower limit of quantification, and finally we performed an analysis of change in hs-TnT that was insensitive to the value of hs-TnT imputed for the lower limit of quantification , ordinal logistic regression adjusted for baseline $\log$ hs-TnT. We also performed analyses incorporating both 12- and 36-week observations as repeated measures, using random intercept linear regression models and ordinal and binary logistic regression models with standard errors adjusted for clustered data. We examined interactions between treatment and week of hs-TnT measurement (12 weeks and 36 weeks). Finally in a multivariable model (adjusting for age, sex, NYHA class, NT-proBNP, heart rate, body mass index, systolic blood pressure, eGFR, prior history or heart failure hospitalization, atrial fibrillation, myocardial infarction, ejection fraction, $\mathrm{E} / \mathrm{E}^{\prime}$, left atrial volume index, left ventricular end-diastolic diameter), we assessed the predictors of baseline $\log$ hs-TnT and change in log hs-TnT at 12 and 36 weeks. All analyses were performed using STATA version 12 (StataCorp, College Station, TX). A $P$ value of $<0.05$ was considered significant.

\section{Results}

At baseline, the majority of patients $(164,55 \%)$ had a hs-TnT level in the range consistent with myocardial injury $(>0.014 \mu \mathrm{g} / \mathrm{L}$; Figure 1). Patients with an elevated hs-TnT were older, more likely to have a history of diabetes mellitus, had lower diastolic 
Table 1. Baseline Characteristics of the Cohort and by hs-TnT Group

\begin{tabular}{|c|c|c|c|c|}
\hline & Overall Cohort & hs-TnT $\leq 0.014 \mu \mathrm{g} / \mathrm{L}$ & hs-TnT $>0.014 \mu \mathrm{g} / \mathrm{L}$ & $P$ Value \\
\hline & $\mathrm{n}=298$ & $\mathrm{n}=134(45 \%)$ & $n=164(55 \%)$ & $\begin{array}{c}\text { hs-TnT } \leq 0.014 \mu \mathrm{g} / \mathrm{L} \text { vs } \\
\text { hs-TnT }>0.014 \mu \mathrm{g} / \mathrm{L}\end{array}$ \\
\hline Age, y & $71(9)$ & $70(9)$ & $72(9)$ & 0.01 \\
\hline Women, \% & $167(56 \%)$ & $86(64 \%)$ & $81(49 \%)$ & 0.01 \\
\hline \multicolumn{5}{|l|}{ NYHA Class } \\
\hline NYHA Class I & $2(1 \%)$ & $1(1 \%)$ & $1(1 \%)$ & \\
\hline NYHA Class II & $236(79 \%)$ & $109(81 \%)$ & $127(77 \%)$ & \\
\hline NYHA Class III & $60(20 \%)$ & $24(18 \%)$ & $36(22 \%)$ & 0.74 \\
\hline \multicolumn{5}{|l|}{ Prior history } \\
\hline Previous admission to hospital for heart failure & $126(42 \%)$ & $51(38 \%)$ & $75(46 \%)$ & 0.18 \\
\hline History of atrial fibrillation & $123(41 \%)$ & $57(43 \%)$ & $66(40 \%)$ & 0.69 \\
\hline Atrial fibrillation at screening ECG & $83(28 \%)$ & $41(31 \%)$ & $42(26 \%)$ & 0.36 \\
\hline History of hypertension & $280(94 \%)$ & $127(95 \%)$ & $153(93 \%)$ & 0.59 \\
\hline History of diabetes mellitus & $114(38 \%)$ & $40(30 \%)$ & $74(45 \%)$ & 0.01 \\
\hline History of myocardial infarction & $62(21 \%)$ & $30(22 \%)$ & $32(20 \%)$ & 0.54 \\
\hline NT-proBNP, pg/mL, median (IQR) & $852(494-1404)$ & $684(376-999)$ & $1145(652-2067)$ & $<0.001$ \\
\hline Heart rate, bpm & $69(13)$ & $69(13)$ & $69(13)$ & 0.97 \\
\hline Body mass index, $\mathrm{kg} / \mathrm{m}^{2}$ & $30(6)$ & $30(6)$ & $30(6)$ & 0.40 \\
\hline Mean sitting systolic BP, mm Hg & $135(14)$ & $133(13)$ & $136(15)$ & 0.13 \\
\hline Mean sitting diastolic BP, mm Hg & $77(9)$ & $80(8)$ & $75(10)$ & $<0.001$ \\
\hline eGFR, mL/min per $1.73 \mathrm{~m}^{2}$ & $65(20)$ & $72(21)$ & $60(18)$ & $<0.001$ \\
\hline eGFR $<60 \mathrm{~mL} / \mathrm{min}$ per $1.73 \mathrm{~m}^{2}$ & $125(43 \%)$ & $36(28 \%)$ & $89(55 \%)$ & $<0.001$ \\
\hline \multicolumn{5}{|l|}{ Baseline treatments } \\
\hline Randomized to LCZ696 & $149(50 \%)$ & $73(55 \%)$ & $76(46 \%)$ & 0.16 \\
\hline ACE inhibitors & $162(54 \%)$ & $75(56 \%)$ & 87 (53\%) & 0.61 \\
\hline ARBs & $118(40 \%)$ & $55(41 \%)$ & $63(38 \%)$ & 0.64 \\
\hline ACE inhibitors or ARBs & $278(93 \%)$ & $129(96 \%)$ & $149(91 \%)$ & 0.06 \\
\hline Diuretics & $298(100 \%)$ & $134(100 \%)$ & $164(100 \%)$ & \\
\hline$\beta$-Blockers & $235(79 \%)$ & $113(84 \%)$ & $122(74 \%)$ & 0.04 \\
\hline Aldosterone antagonists & $63(21 \%)$ & $25(19 \%)$ & $38(23 \%)$ & 0.34 \\
\hline
\end{tabular}

Values are mean with SD and $\mathrm{n}(\%)$ unless specified. ACE indicates angiotensin-converting enzyme; ARB, angiotensin receptor blocker; eGFR, estimated glomerular filtration rate; hs-TnT, high-sensitivity troponin T; NT-proBNP, N-terminal pro-B-type natriuretic peptide; and NYHA, New York Heart Association.

blood pressure, and were less likely to be taking a $\beta$-blocker (Table1). In addition, those with higher hs-TnT had higher NTproBNP $(r=0.43 ; P<0.001)$ and lower eGFR $(r=-0.35 ; P<0.001)$.

We noted several differences in cardiac structure in patients with an elevated troponin (Table 2), including larger left atrial diameter, left ventricular volume, and greater left ventricular mass. We observed no differences in measures of cardiac systolic or diastolic function, including left ventricular ejection fraction, global longitudinal strain, $\mathrm{E}^{\prime}$, or $\mathrm{E} / \mathrm{E}^{\prime}$ ratios among patients with and without elevated hs-TnT. Tricuspid regurgitant velocity was higher in the group with an elevated hs-TnT.

Over the course of 36 weeks, hs-TnT fell in both the LCZ696 and the valsartan groups (Figure 2), with the majority of patients still having a hs-TnT in the myocardial injury range (Figure 1). The characteristics of those whose hs-TnT level fell, remained unchanged, or increased are given in Table 3. Change in hs-TnT correlated with change in NT-proBNP at 36 weeks $(r=0.35$; $P<0.001)$, but not at 12 weeks $(r=0.12 ; P=0.06)$. We found no correlation between changes in systolic blood pressure and
hs-TnT at 12 weeks $(r=-0.09 ; P=0.15)$ and weak correlation between change in systolic blood pressure and hs-TnT at 36 weeks $(r=-0.15 ; P=0.03)$. There was no association between change in hs-TnT at 12 or 36 weeks and change in $\mathrm{E}^{\prime}(P=0.16$ and $P=0.81$, respectively) or change in $\mathrm{E} / \mathrm{E}^{\prime}(P=0.11$ and $P=0.34$, respectively). In a multivariable model, female sex $(P=0.004)$, prior MI $(P=0.016)$, and higher eGFR $(P<0.001)$ were associated with lower hs-TnT at baseline, whereas higher NT-proBNP was associated with higher hs-TnT at baseline $(P<0.001)$. At 12 weeks, except for baseline hs-TnT, no variables were associated with change in hs-TnT. At 36 weeks in addition to baseline hs-TnT, NT-proBNP was associated with change in log hs-TnT (coefficient -0.14 per $1 \log$ unit increase; $P=0.002$ ) as was age (coefficient 0.02 per 1 year increase; $P<0.001$ ), systolic blood pressure (coefficient -0.01 per $1 \mathrm{mmHg}$ change; $P=0.008$ ), eGFR (coefficient -0.01 per $1 \mathrm{~mL} / \mathrm{min} / \mathrm{m}^{2}$ increase; $P<0.001$ ), and $\mathrm{E} / \mathrm{E}^{\prime}$ (coefficient 0.02 per 1 unit increase; $P=0.02$ ).

Compared with valsartan, treatment with LCZ696 was associated with greater reduction in hs-TnT (Tables 4 and 5; 
Table 2. Echocardiographic Characteristics of the Cohort and by hs-TnT

\begin{tabular}{|c|c|c|c|c|}
\hline & Overall Cohort & hs-TnT $\leq 0.014 \mu \mathrm{g} / \mathrm{L}$ & hs-TnT $>0.014 \mu \mathrm{g} / \mathrm{L}$ & $P$ Value \\
\hline & $\mathrm{n}=298$ & $\mathrm{n}=134(45 \%)$ & $\mathrm{n}=164(55 \%)$ & $\begin{array}{c}\text { hs-TnT } \leq 0.014 \mu \mathrm{g} / \mathrm{L} \text { vs } \\
\text { hs-TnT }>0.014 \mu \mathrm{g} / \mathrm{L}\end{array}$ \\
\hline $\mathrm{E}^{\prime}, \mathrm{cm} / \mathrm{s}$ & $7.5(2.7)$ & $7.3(2.6)$ & $7.6(2.9)$ & 0.46 \\
\hline$E / A$ & $1.1(0.6)$ & $1.1(0.6)$ & $1.1(0.7)$ & 1.00 \\
\hline $\mathrm{E} / \mathrm{E}^{\prime}$ & $12.6(6.0)$ & $12.9(6.4)$ & $12.2(5.5)$ & 0.44 \\
\hline LA diameter, $\mathrm{cm}$ & $3.7(0.5)$ & $3.6(0.4)$ & $3.8(0.5)$ & $<0.05$ \\
\hline LA volume, $\mathrm{mL}$ & $67(26)$ & $64(23)$ & $69(29)$ & 0.17 \\
\hline Left atrial volume index, $\mathrm{mL} / \mathrm{m}^{2}$ & $36(13)$ & $35(12)$ & $37(15)$ & 0.28 \\
\hline Left ventricular end-diastolic volume, mL & $113(29)$ & $109(29)$ & $117(28)$ & 0.04 \\
\hline Left ventricular end-diastolic volume index, $\mathrm{mL} / \mathrm{m}^{2}$ & $60(14)$ & $59(15)$ & $62(13)$ & 0.13 \\
\hline Left ventricular end-systolic volume, $\mathrm{mL}$ & $48(18)$ & $46(18)$ & $49(19)$ & 0.28 \\
\hline Left ventricular end-systolic volume index, $\mathrm{mL} / \mathrm{m}^{2}$ & $26(9)$ & $25(10)$ & $26(9)$ & 0.56 \\
\hline Left ventricular mass, g & $145(40)$ & $134(33)$ & $157(44)$ & $<0.001$ \\
\hline Left ventricular mass index, $\mathrm{g} / \mathrm{m}^{2}$ & $77(21)$ & $72(18)$ & $83(23)$ & $<0.001$ \\
\hline Relative wall thickness, $\%$ & $0.37(0.07)$ & $0.36(0.06)$ & $0.37(0.08)$ & 0.24 \\
\hline Tricuspid regurgitant velocity, $\mathrm{m} / \mathrm{s}$ & $2.5(0.4)$ & $2.4(0.4)$ & $2.6(0.4)$ & 0.005 \\
\hline Left atrial global strain, \% & $21.1(8.0)$ & $21.2(8.4)$ & $21.1(7.7)$ & 0.91 \\
\hline Left ventricular global longitudinal strain, \% & $-14.7(3.3)$ & $-14.9(3.4)$ & $-14.5(3.3)$ & 0.38 \\
\hline Left ventricular ejection fraction, \% & $58(8)$ & $58(8)$ & $58(8)$ & 0.66 \\
\hline Left ventricular ejection fraction $\geq 45 \%$ and $<50 \%$ & $37(14 \%)$ & $18(14 \%)$ & $19(13 \%)$ & 0.83 \\
\hline
\end{tabular}

hs-TnT indicates high-sensitivity troponin T; and LA, left atrium.

Figure 2). The ratio of change in hs-TnT with LCZ696 in comparison with valsartan was 0.88 (95\% confidence interval, 0.77 $1.00, P=0.05)$ at 12 weeks and $0.86(95 \%$ confidence interval, $0.75-0.99, P=0.03)$ at 36 weeks using an imputed value of half the lower limit of quantification in those with a hs-TnT below this limit. We observed a similar degree of reduction in hs-TnT by analyzing hs-TnT as a binary variable in a logistic regression model, as an ordinal variable in an ordinal logistic regression model, and after imputing a value for those under the limit of quantification that was closer to the limit of quantification of hs-TnT (Table 5). When repeated measures models were used, a consistent treatment effect of LCZ696 on hs-TnT levels was observed (Tables 4 and 5), with no significant interactions between treatment effect and follow-up time.

\section{Discussion}

In a well-characterized cohort of patients with HFPEF, we found that the majority of patients had a hs-TnT concentration above the threshold for diagnosis of myocardial injury. Higher hs-TnT concentrations were associated with several features that are known to be related to worse outcome in HFpEF, including increasing age, higher NT-proBNP, and lower eGFR, and were associated with abnormalities of cardiac structure. Treatment with the angiotensin receptor neprilysin inhibitor LCZ696 resulted in greater reduction in hs-TnT levels for 36 weeks in comparison with treatment with valsartan, suggesting that LCZ696 may reduce this measure of myocardial injury in HFpEF via potentiation of natriuretic peptides ${ }^{17}$ (see below).

Although elevated troponin is now well described in $\mathrm{HFrEF}^{3}$ prior studies on the relationship between troponin and HFpEF have concentrated on patients who are hospitalized or acutely decompensated. ${ }^{8-10}$ Our population was similar to other trials of patients with $\mathrm{HFpEF}^{18}$ but generally younger with fewer comorbidities than community-based cohorts of patients with HFpEF. ${ }^{19}$ We found that $58 \%$ had a hs-TnT level in the myocardial injury range, a result similar to that observed in HFrEF. In the Controlled Rosuvastatin Multinational Trial in HF (CORONA), $49 \%$ of patients had a hs-TnT level above the limit for the detection of myocardial injury $(0.014 \mu \mathrm{g} / \mathrm{L})$ using a Roche assay. ${ }^{6}$ In the Valsartan Heart Failure Trial (Val-HeFT) ${ }^{7}$ and the Gruppo Italiano per lo Studio della Sopravvivenza nell'Insufficienza Cardiaca-Heart Failure trial (GISSI-HF),

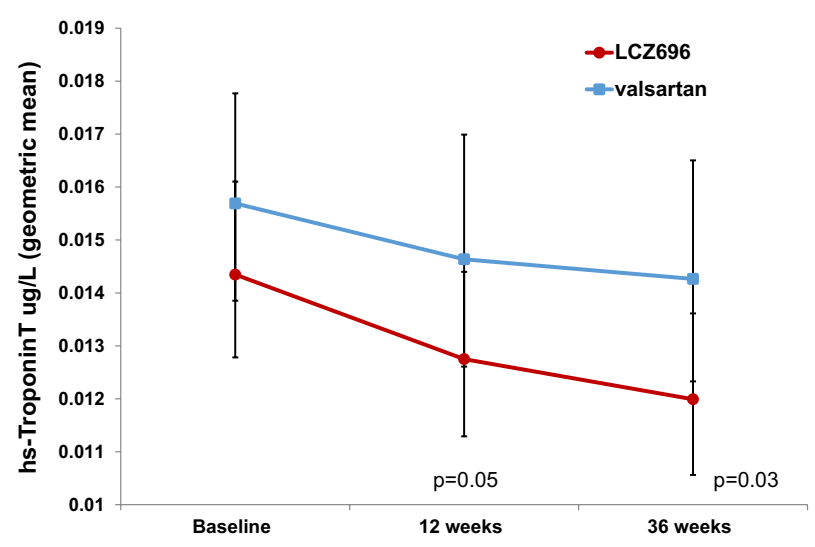

Figure 2. High-sensitivity troponin T (hs-TnT) levels by treatment group. Geometric mean (error bars represent 95\% confidence intervals) of hs-TnT at baseline, 12 weeks, and 36 weeks by randomized treatment. Adjusted $P$ values for the effect of LCZ696 vs valsartan on hs-TnT adjusted for the stratification variables of prior angiotensin-converting enzyme/angiotensin receptor blocker and region of randomization. hs-TnT analyzed imputing half the lower limit of quantification $(<0.013 \mu \mathrm{g} / \mathrm{L})$ for those with a value below the lower limit of quantification . 
Table 3. Characteristics of Patients According to Whether hs-TnT Fell Was Unchanged or Increased at 36 wk

\begin{tabular}{|c|c|c|c|c|}
\hline & hs-TnT Fell & hs-TnT Unchanged & hs-TnT Increased & \\
\hline & $\mathrm{n}=72$ & $n=81$ & $\mathrm{n}=72$ & $P$ for Trend \\
\hline Age, y & $70 \pm 8$ & $70 \pm 9$ & $74 \pm 8$ & 0.003 \\
\hline Women, \% & $36(50 \%)$ & $52(65 \%)$ & $43(61 \%)$ & 0.20 \\
\hline NYHA Class & & & & 0.09 \\
\hline NYHA Class I & $2(3 \%)$ & $0(0 \%)$ & $0(0 \%)$ & \\
\hline NYHA Class II & $59(82 \%)$ & $69(86 \%)$ & $54(76 \%)$ & \\
\hline NYHA Class III & $11(15 \%)$ & $11(14 \%)$ & $17(24 \%)$ & \\
\hline \multicolumn{5}{|l|}{ Prior History } \\
\hline Previous admission to hospital for heart failure & $29(40 \%)$ & $29(36 \%)$ & $28(39 \%)$ & 0.92 \\
\hline History of atrial fibrillation & $29(40 \%)$ & $39(49 \%)$ & $32(45 \%)$ & 0.56 \\
\hline Atrial fibrillation at screening ECG & $17(24 \%)$ & $27(34 \%)$ & $23(32 \%)$ & 0.25 \\
\hline History of hypertension & $66(92 \%)$ & $78(98 \%)$ & $66(93 \%)$ & 0.74 \\
\hline History of diabetes mellitus & $29(40 \%)$ & $25(31 \%)$ & $27(38 \%)$ & 0.78 \\
\hline History of myocardial infarction & $15(21 \%)$ & $20(25 \%)$ & $13(18 \%)$ & 0.72 \\
\hline NT-proBNP, pg/mL, median (IQR) & $1148(646-2148)$ & 638 (364-999) & 891 (601-1435) & 0.18 \\
\hline Heart rate, bpm & $71 \pm 14$ & $69 \pm 12$ & $66 \pm 12$ & 0.025 \\
\hline Body mass index, $\mathrm{kg} / \mathrm{m}^{2}$ & $30 \pm 6$ & $31 \pm 6$ & $31 \pm 5$ & 0.58 \\
\hline Mean sitting systolic $\mathrm{BP}, \mathrm{mm} \mathrm{Hg}$ & $136 \pm 12$ & $135 \pm 12$ & $136 \pm 16$ & 0.92 \\
\hline Mean sitting diastolic BP, mm Hg & $77 \pm 9$ & $81 \pm 9$ & $75 \pm 10$ & 0.31 \\
\hline eGFR, mL/min per $1.73 \mathrm{~m}^{2}$ & $63 \pm 18$ & $75 \pm 20$ & $60 \pm 18$ & 0.55 \\
\hline eGFR $<60 \mathrm{~mL} / \mathrm{min}$ per $1.73 \mathrm{~m}^{2}$ & $33(46 \%)$ & $18(23 \%)$ & $35(49 \%)$ & 0.68 \\
\hline \multicolumn{5}{|l|}{ Baseline treatments } \\
\hline Randomized to LCZ696 & $40(56 \%)$ & $43(54 \%)$ & $31(44 \%)$ & 0.16 \\
\hline ACE inhibitors & $38(53 \%)$ & $42(52 \%)$ & $38(54 \%)$ & 0.93 \\
\hline ARBs & $28(39 \%)$ & $35(44 \%)$ & $31(44 \%)$ & 0.56 \\
\hline ACE inhibitors or ARBs & $66(92 \%)$ & $77(96 \%)$ & $67(94 \%)$ & 0.49 \\
\hline$\beta$-blockers & $51(71 \%)$ & $70(88 \%)$ & $57(80 \%)$ & 0.16 \\
\hline Aldosterone antagonists & $15(21 \%)$ & $15(19 \%)$ & $14(20 \%)$ & 0.87 \\
\hline
\end{tabular}

ACE indicates angiotensin-converting enzyme; ARB, angiotensin receptor blocker; eGFR, estimated glomerular filtration rate; hs-TnT, highsensitivity troponin T; NT-proBNP, N-terminal pro-B-type natriuretic peptide; and NYHA, New York Heart Association.

$47 \%$ and $64 \%$ of patients had a hs-TnT level above the limit of detection for myocardial injury $(0.0135 \mu \mathrm{g} / \mathrm{L})$ using a Roche hs-TnT assay. ${ }^{7}$ By comparison, in a population-based study of men and women aged 54 to 74 years, $7.4 \%$ of individuals had a $\mathrm{hs}-\mathrm{TnT}$ in the myocardial injury range $(>0.014 \mu \mathrm{g} / \mathrm{L}) .^{20}$

Table 4. Ratios of Change in hs-TnT in LCZ696 Group vs Valsartan Group at 12 and 36 wk Adjusted for Baseline hs$\mathrm{TnT}$ and the Stratification Variables of Region and Prior ACE Inhibitor or ARB Use

\begin{tabular}{lcc}
\hline Primary Analysis & $\begin{array}{c}\text { Ratio of Change in hs-TnT } \\
\text { (LCZ696 vs Valsartan) }\end{array}$ & $\begin{array}{c}P \\
\text { Value }\end{array}$ \\
\hline $\begin{array}{l}\text { Linear regression of hs-TnT } \\
\text { at } 12 \text { wk (imputing } 0.0065 \mu \mathrm{g} / \mathrm{L})\end{array}$ & $0.88(0.77-1.00)$ & 0.05 \\
$\begin{array}{l}\text { Linear regression of hs-TnT } \\
\text { at } 36 \text { wk (imputing } 0.0065 \mu \mathrm{g} / \mathrm{L})\end{array}$ & $0.86(0.75-0.99)$ & 0.03 \\
$\begin{array}{l}\text { Linear regression of hs-TnT- } \\
\text { Repeated Measures Model } \\
\text { (imputing } 0.0065 \mu \mathrm{g} / \mathrm{L})\end{array}$ & $0.87(0.78-0.97)$ & $0.01^{*}$ \\
\hline
\end{tabular}

ACE indicates angiotensin-converting enzyme; ARB, angiotensin receptor blocker; and hs-TnT, high-sensitivity troponin T.

*No significant interaction between in treatment effect and week of follow-up.
Unlike ADHF where troponin elevation may be related to an acute precipitant, and acute decompensation can lead to volume overload and increased ventricular wall stress, the finding of elevated troponin in stable HFpEF is suggestive of ongoing subclinical myocardial injury. Few patients had an acute precipitant to explain the troponin elevations. In the patients without a serious adverse event during the trial, 54\% had a hs-TnT level in the injury range at baseline, $49 \%$ at 12 weeks, and $47 \%$ at 36 weeks. Furthermore, only $24 \%$ of patients with a hs-TnT in the injury range at 36 weeks had experienced a serious adverse event at any point in the study. However, ongoing myocardial injury may be part of the process that explains the high morbidity and mortality in HFpEF. ${ }^{21}$ The finding of increased left ventricular size and mass, increased left atrial size, and elevated NT-proBNP in patients with elevated troponin suggests that increased wall stress may be a potential mechanism for the observed elevation. Stretching of myocytes can lead to the release of angiotensin II, increased oxidative stress, architectural rearrangement, and eventual cell death. ${ }^{22,23}$ Moreover, troponin can be released from viable myocytes when stretched or subjected to ischemia. ${ }^{24}$ Higher hs-TnT was also associated with higher myocardial mass and 
Table 5. Ratios of Change and Odds Ratios in LCZ696 Group vs Valsartan Group at 12 and $\mathbf{3 6}$ wk Adjusted for Baseline hsTnT and the Stratification Variables of Region and Prior ACE Inhibitor or ARB Use

\begin{tabular}{|c|c|c|}
\hline Sensitivity Analyses & $\begin{array}{l}\text { Ratio of Change }{ }^{*} / 0 \text { dds Ratio } † \\
\text { (LCZ696 vs Valsartan) }\end{array}$ & $P$ Value \\
\hline $\begin{array}{l}\text { Linear regression of hs-TnT at } \\
12 \text { wk (imputing } 0.012 \mu \mathrm{g} / \mathrm{L} \text { ) }\end{array}$ & $0.90(0.81-0.98)$ & 0.02 \\
\hline $\begin{array}{l}\text { Linear regression of hs- } \mathrm{TnT} \text { at } \\
36 \text { wk (imputing } 0.012 \mu \mathrm{g} / \mathrm{L} \text { ) }\end{array}$ & $0.91(0.84-1.00)$ & 0.05 \\
\hline $\begin{array}{l}\text { Linear regression of hs-TnT- } \\
\text { Repeated Measures Model } \\
\text { (imputing } 0.012 \mu \mathrm{g} / \mathrm{L} \text { ) }\end{array}$ & $0.90(0.84-0.97)$ & $0.005 \ddagger$ \\
\hline $\begin{array}{l}\text { Ordered logistic regression of } \\
\text { hs-TnT at } 12 \text { wk }\end{array}$ & $0.71(0.44-1.16)$ & 0.17 \\
\hline $\begin{array}{l}\text { Ordered logistic regression of } \\
\text { hs-TnT at } 36 \text { wk }\end{array}$ & $0.60(0.35-1.01)$ & 0.06 \\
\hline $\begin{array}{l}\text { Ordered logistic regression of } \\
\text { hs-TnT-Repeated Measures } \\
\text { Model }\end{array}$ & $0.65(0.44-0.97)$ & $0.04 \ddagger$ \\
\hline $\begin{array}{l}\text { Logistic regression hs- } \\
\mathrm{TnT}>0.014 \mu \mathrm{g} / \mathrm{L} \text { at } 12 \mathrm{wk}\end{array}$ & $0.79(0.41-1.52)$ & 0.47 \\
\hline $\begin{array}{l}\text { Logistic regression hs- } \\
\mathrm{TnT}>0.014 \mu \mathrm{g} / \mathrm{L} \text { at } 36 \mathrm{wk}\end{array}$ & $0.67(0.34-1.32)$ & 0.25 \\
\hline $\begin{array}{l}\text { Logistic regression hs- } \\
\text { TnT }>0.014 \mu \mathrm{g} / \mathrm{L} \text {-Repeated } \\
\text { Measures Model }\end{array}$ & $0.73(0.41-1.29)$ & $0.28 \ddagger$ \\
\hline
\end{tabular}

ACE indicates angiotensin-converting enzyme; ARB, angiotensin receptor blocker; and hs-TnT, high-sensitivity troponin T.

*Ratio of change refers to the estimate of treatment effect from linear regression. †Odds ratio refers to the estimate of treatment effect from the ordered logistic regression and logistic regression.

$\ddagger$ No significant interaction between in treatment effect and week of follow-up.

tricuspid regurgitant velocity. The relative contribution of myocardial hypertrophy and fibrosis, ${ }^{25}$ the right heart, ${ }^{23,26}$ and the microcirculation and repetitive ischemi $\mathrm{a}^{27}$ to the troponin concentrations observed remains to be determined.

We found that 36 weeks of therapy with LCZ696 compared with valsartan resulted in a modest reduction in troponin. These findings are consistent with the previously reported findings from the PARAMOUNT trial, ${ }^{14}$ including reduction of NT-proBNP at 12 weeks, and reduction in left atrial size and improvement in NYHA class at 36 weeks. This suggests that neprilysin inhibition by LCZ696 and potentiation of natriuretic peptides leading to a reduction in wall stress may reduce troponin leakage in parallel with reduction in NT-proBNP and left atrial size. Although change in hs-TnT correlated with change in systolic blood pressure, the effect of treatment on hs-TnT was independent of the changes in blood pressure in keeping with our prior observations on the action of the drug on NT-proBNP and echocardiographic parameters. ${ }^{28}$ Whether elevated troponin levels are associated with poorer prognosis in HFpEF is unknown, although this is likely given the associations that have been observed in $\mathrm{HFrEF}^{7}$ and possibly $\mathrm{HFpEF}$ in the acute decompensated setting. ${ }^{9}$ Moreover, whether a therapy that reduces hs-TnT levels would reduce morbidity and mortality in this population is unclear.

Some limitations of this analysis should be noted. PARAMOUNT was a relatively short-term study, and we thus cannot determine whether elevations in troponin are related to prognosis. Our data provide no direct insight into the mechanisms of troponin release in $\mathrm{HFpEF}$, although the relationship among troponin, cardiac structure, and NT-proBNP suggest that elevated wall stress may be a common mechanism to account for elevation in both biomarkers. With limited information on right-sided hemodynamic indices, we cannot assess the contribution of the pulmonary vasculature and right side of the heart to the raised troponin levels we observed. ${ }^{26}$ Our cohort may represent patients with more severe HF as entry into the trial required an NT-proBNP level of $>400 \mathrm{pg} / \mathrm{mL}$. Therefore, our results may not be applicable to patients with HFpEF and low NT-proBNP levels. The ejection fraction in this trial was $>50 \%$ in $86 \%$ of patients. We could not specifically examine those patients with an ejection fraction at the lower end of the ejection fraction spectrum (45\% to 50\%).

In summary, we observed elevation in hs-TnT in a well-characterized HFpEF population, which was associated with larger left ventricular and atrial size, as well as higher NT-proBNP. These findings suggest that ongoing myocardial chronic troponin release, either because of myocyte stretch or injury, may contribute to the pathophysiology of HFpEF. LCZ696 reduced hs-TnT modestly compared with valsartan. Whether chronic reduction in hs-TnT can be achieved and whether this would lead to improved outcomes in HFpEF remains to be tested.

\section{Sources of Funding}

The PARAMOUNT trial was funded by Novartis Pharmaceuticals, East Hanover, NJ.

\section{Disclosures}

Drs Solomon, Zile, Pieske, Voors, Shah, Packer, and McMurray have received research support and have consulted for Novartis. Drs Shi, Prescott, and Lefkowitz are employees of Novartis. The other authors report no conflicts.

\section{References}

1. Latini R, Masson S, Anand IS, Missov E, Carlson M, Vago T, Angelici L, Barlera S, Parrinello G, Maggioni AP, Tognoni G, Cohn JN; ValHeFT Investigators. Prognostic value of very low plasma concentrations of troponin $\mathrm{T}$ in patients with stable chronic heart failure. Circulation. 2007;116:1242-1249.

2. Januzzi JL Jr, Filippatos G, Nieminen M, Gheorghiade M. Troponin elevation in patients with heart failure: on behalf of the third Universal Definition of Myocardial Infarction Global Task Force: Heart Failure Section. Eur Heart J. 2012;33:2265-2271.

3. Kociol RD, Pang PS, Gheorghiade M, Fonarow GC, O'Connor CM, Felker GM. Troponin elevation in heart failure prevalence, mechanisms, and clinical implications. J Am Coll Cardiol. 2010;56:1071-1078.

4. Perna ER, Macin SM, Canella JP, Augier N, Stival JL, Cialzeta JR, Pitzus AE, Garcia EH, Obregón R, Brizuela M, Barbagelata A. Ongoing myocardial injury in stable severe heart failure: value of cardiac troponin T monitoring for high-risk patient identification. Circulation. 2004;110:2376-2382.

5. Löwbeer C, Gustafsson SA, Seeberger A, Bouvier F, Hulting J. Serum cardiac troponin $\mathrm{T}$ in patients hospitalized with heart failure is associated with left ventricular hypertrophy and systolic dysfunction. Scand J Clin Lab Invest. 2004;64:667-676.

6. Gravning J, Askevold ET, Nymo SH, Ueland T, Wikstrand J, McMurray JJ, Aukrust P, Gullestad L, Kjekshus J; CORONA Study Group. Prognostic effect of high-sensitive troponin $\mathrm{T}$ assessment in elderly patients with chronic heart failure: results from the CORONA trial. Circ Heart Fail. 2014;7:96-103.

7. Masson S, Anand I, Favero C, Barlera S, Vago T, Bertocchi F, Maggioni AP, Tavazzi L, Tognoni G, Cohn JN, Latini R; Valsartan Heart Failure Trial (Val-HeFT) and Gruppo Italiano per lo Studio della Sopravvivenza 
nell'Insufficienza Cardiaca-Heart Failure (GISSI-HF) Investigators. Serial measurement of cardiac troponin $\mathrm{T}$ using a highly sensitive assay in patients with chronic heart failure: data from 2 large randomized clinical trials. Circulation. 2012;125:280-288.

8. Perna ER, Aspromonte N, Cimbaro Canella JP, Di Tano G, Macin SM, Feola M, Coronel ML, Milani L, Parras JI, Milli M, García EH, Valle R. Minor myocardial damage is a prevalent condition in patients with acute heart failure syndromes and preserved systolic function with long-term prognostic implications: a report from the CIAST-HF (Collaborative Italo-Argentinean Study on cardiac Troponin T in Heart Failure) study. $J$ Card Fail. 2012;18:822-830.

9. Dinh W, Nickl W, Füth R, Lankisch M, Hess G, Zdunek D, Scheffold T, Barroso MC, Tiroch K, Ziegler D, Seyfarth M. High sensitive troponin $\mathrm{T}$ and heart fatty acid binding protein: novel biomarker in heart failure with normal ejection fraction? A cross-sectional study. BMC Cardiovasc Disord. 2011;11:41.

10. Shah RV, Chen-Tournoux AA, Picard MH, Januzzi JL. Association between troponin $\mathrm{T}$ and impaired left ventricular relaxation in patients with acute decompensated heart failure with preserved systolic function. Eur J Echocardiogr. 2009;10:765-768.

11. Zile MR, Baicu CF, Gaasch WH. Diastolic heart failure-abnormalities in active relaxation and passive stiffness of the left ventricle. $N$ Engl $\mathrm{J}$ Med. 2004;350:1953-1959.

12. Zile MR, Gottdiener JS, Hetzel SJ, McMurray JJ, Komajda M, McKelvie R, Baicu CF, Massie BM, Carson PE; I-PRESERVE Investigators. Prevalence and significance of alterations in cardiac structure and function in patients with heart failure and a preserved ejection fraction. Circulation. 2011;124:2491-2501.

13. Kraigher-Krainer E, Shah AM, Gupta DK, Santos A, Claggett B, Pieske B, Zile MR, Voors AA, Lefkowitz MP, Packer M, McMurray JJ, Solomon SD; PARAMOUNT Investigators. Impaired systolic function by strain imaging in heart failure with preserved ejection fraction. $J \mathrm{Am}$ Coll Cardiol. 2014;63:447-456.

14. Solomon SD, Zile M, Pieske B, Voors A, Shah A, Kraigher-Krainer E, Shi V, Bransford T, Takeuchi M, Gong J, Lefkowitz M, Packer M, McMurray $\mathrm{JJ}$; Prospective comparison of ARNI with ARB on Management Of heart failUre with preserved ejectioN fracTion (PARAMOUNT) Investigators. The angiotensin receptor neprilysin inhibitor LCZ696 in heart failure with preserved ejection fraction: a phase 2 double-blind randomised controlled trial. Lancet. 2012;380:1387-1395.

15. Metra M, Cotter G, Davison BA, Felker GM, Filippatos G, Greenberg BH, Ponikowski P, Unemori E, Voors AA, Adams KF Jr, Dorobantu MI, Grinfeld L, Jondeau G, Marmor A, Masip J, Pang PS, Werdan K, Prescott MF, Edwards C, Teichman SL, Trapani A, Bush CA, Saini R, Schumacher C, Severin T, Teerlink JR; RELAX-AHF Investigators. Effect of serelaxin on cardiac, renal, and hepatic biomarkers in the Relaxin in Acute Heart Failure (RELAX-AHF) development program: correlation with outcomes. J Am Coll Cardiol. 2013;61:196-206.

16. Lang RM, Bierig M, Devereux RB, Flachskampf FA, Foster E, Pellikka PA, Picard MH, Roman MJ, Seward J, Shanewise JS, Solomon SD, Spencer KT, Sutton MS, Stewart WJ; Chamber Quantification Writing Group; American Society of Echocardiography's Guidelines and
Standards Committee; European Association of Echocardiography. Recommendations for chamber quantification: a report from the American Society of Echocardiography's Guidelines and Standards Committee and the Chamber Quantification Writing Group, developed in conjunction with the European Association of Echocardiography, a branch of the European Society of Cardiology. J Am Soc Echocardiogr. 2005;18:1440-1463.

17. Burley DS, Baxter GF. B-type natriuretic peptide at early reperfusion limits infarct size in the rat isolated heart. Basic Res Cardiol. 2007;102:529-541.

18. Massie BM, Carson PE, McMurray JJ, Komajda M, McKelvie R, Zile MR, Anderson S, Donovan M, Iverson E, Staiger C, Ptaszynska A; I-PRESERVE Investigators. Irbesartan in patients with heart failure and preserved ejection fraction. $N$ Engl J Med. 2008;359:2456-2467.

19. Owan TE, Hodge DO, Herges RM, Jacobsen SJ, Roger VL, Redfield MM. Trends in prevalence and outcome of heart failure with preserved ejection fraction. N Engl J Med. 2006;355:251-259.

20. Saunders JT, Nambi V, de Lemos JA, Chambless LE, Virani SS, Boerwinkle E, Hoogeveen RC, Liu X, Astor BC, Mosley TH, Folsom AR, Heiss G, Coresh J, Ballantyne CM. Cardiac troponin T measured by a highly sensitive assay predicts coronary heart disease, heart failure, and mortality in the Atherosclerosis Risk in Communities Study. Circulation. 2011;123:1367-1376

21. Campbell RT, Jhund PS, Castagno D, Hawkins NM, Petrie MC, McMurray JJ. What have we learned about patients with heart failure and preserved ejection fraction from DIG-PEF, CHARM-preserved, and I-PRESERVE? J Am Coll Cardiol. 2012;60:2349-2356.

22. Cheng W, Li B, Kajstura J, Li P, Wolin MS, Sonnenblick EH, Hintze TH, Olivetti G, Anversa P. Stretch-induced programmed myocyte cell death. J Clin Invest. 1995;96:2247-2259.

23. Nadal-Ginard B, Kajstura J, Leri A, Anversa P. Myocyte death, growth, and regeneration in cardiac hypertrophy and failure. Circ Res. 2003:92:139-150.

24. Hessel MH, Atsma DE, van der Valk EJ, Bax WH, Schalij MJ, van der Laarse A. Release of cardiac troponin I from viable cardiomyocytes is mediated by integrin stimulation. Pflugers Arch. 2008;455:979-986.

25. Kawasaki T, Sakai C, Harimoto K, Yamano M, Miki S, Kamitani T. Usefulness of high-sensitivity cardiac troponin $\mathrm{T}$ and brain natriuretic peptide as biomarkers of myocardial fibrosis in patients with hypertrophic cardiomyopathy. Am J Cardiol. 2013;112:867-872.

26. Völkers M, Rohde D, Zelniker T, Weiss CS, Giannitsis E, Katus HA, Meyer FJ. High-sensitive Troponin $\mathrm{T}$ increase after exercise in patients with pulmonary arterial hypertension. BMC Pulm Med. 2013;13:28.

27. Borlaug BA, Paulus WJ. Heart failure with preserved ejection fraction: pathophysiology, diagnosis, and treatment. Eur Heart J. 2011;32:670-679.

28. Jhund PS, Claggett B, Packer M, Zile MR, Voors AA, Pieske B, Lefkowitz M, Shi V, Bransford T, McMurray JJ, Solomon SD. Independence of the blood pressure lowering effect and efficacy of the angiotensin receptor neprilysin inhibitor, LCZ696, in patients with heart failure with preserved ejection fraction: an analysis of the PARAMOUNT trial. Eur $J$ Heart Fail. 2014;16:671-677.

\section{CLINICAL PERSPECTIVE}

Elevated high-sensitivity troponin is associated with increasing disease severity in patients with stable heart failure with reduced ejection fraction, but less is known about the association in heart failure with preserved ejection fraction. In this analysis of the Prospective comparison of angiotensin receptor neprilysin inhibitor with angiotensin receptor blocker on Management Of heart failUre with preserved ejectioN fracTion (PARAMOUNT) trial, we found that high-sensitivity tropo$\operatorname{nin} \mathrm{T}$ (hs-TnT) was elevated in the myocardial injury range $(>0.014 \mu \mathrm{g} / \mathrm{L})$ in $55 \%$ of patients. Higher hs-TnT was associated with higher N-terminal pro-brain natriuretic peptide, lower estimated glomerular filtration rate, and larger left atrial size, left ventricular volume and mass. Treatment with the novel angiotensin receptor neprilysin inhibitor LCZ696 reduced hs-TnT to a greater extent at 12 weeks (12\% reduction; $P=0.05$ ) and at 36 weeks (14\% reduction; $P=0.03$ ) compared with valsartan. A large proportion of patients with heart failure with preserved ejection fraction in this trial had hs-TnT levels in the myocardial injury range. Although hs-TnT was associated with abnormalities of cardiac structure, function, and elevated baseline N-terminal pro-brain natriuretic peptide, the finding that treatment with LCZ696 lowered hs-TnT in parallel with lowering $\mathrm{N}$-terminal pro-brain natriuretic peptide and left atrial size suggest that the drug may also reduce this marker of myocardial injury in heart failure with preserved ejection fraction. 


\section{Elevation in High-Sensitivity Troponin $\mathrm{T}$ in Heart Failure and Preserved Ejection Fraction and Influence of Treatment With the Angiotensin Receptor Neprilysin Inhibitor LCZ696}

Pardeep S. Jhund, Brian L. Claggett, Adriaan A. Voors, Michael R. Zile, Milton Packer, Burkert M. Pieske, Elisabeth Kraigher-Krainer, Amil M. Shah, Margaret F. Prescott, Victor Shi, Marty Lefkowitz, John J.V. McMurray and Scott D. Solomon for the PARAMOUNT Investigators*

Circ Heart Fail. 2014;7:953-959; originally published online October 2, 2014; doi: 10.1161/CIRCHEARTFAILURE.114.001427

Circulation: Heart Failure is published by the American Heart Association, 7272 Greenville Avenue, Dallas, TX 75231

Copyright (c) 2014 American Heart Association, Inc. All rights reserved.

Print ISSN: 1941-3289. Online ISSN: 1941-3297

The online version of this article, along with updated information and services, is located on the World Wide Web at:

http://circheartfailure.ahajournals.org/content/7/6/953

Data Supplement (unedited) at:

http://circheartfailure.ahajournals.org/content/suppl/2014/10/02/CIRCHEARTFAILURE.114.001427.DC1

\footnotetext{
Permissions: Requests for permissions to reproduce figures, tables, or portions of articles originally published in Circulation: Heart Failure can be obtained via RightsLink, a service of the Copyright Clearance Center, not the Editorial Office. Once the online version of the published article for which permission is being requested is located, click Request Permissions in the middle column of the Web page under Services. Further information about this process is available in the Permissions and Rights Question and Answer document.
}

Reprints: Information about reprints can be found online at: http://www.lww.com/reprints

Subscriptions: Information about subscribing to Circulation: Heart Failure is online at: http://circheartfailure.ahajournals.org//subscriptions/ 


\section{Supplemental File}




\section{PARAMOUNT Investigators}

Dr. Noemi Zucchiatti, DIM Clinica Privada, Buenos Aires, Argentina; Dr. Horacio Jure, Clinica Chutro, Cordoba, Argentina; Dr. Rodolfo Milesi, Sanatorio Santa Fe, Santa Fe, Argentina; Dr. Emilio Kuschnir, Instituto del Corazon, Cordoba, Argentina; Dr. Eduardo Perna, Institudo de Cardiologia J. F. Cabral, Corrientes, Argentina; Dr. Claudio Majul, Hospital Santojanni, Buenos Aires, Argentina; Dr. Javier Llanos,Instituto de Investigaciones Clinicas, Rosario, Argentina; Dr. Alejo Grosse, Alejo Grosse \& Carlos Rojas Investigaciones Clinicas, San Miguel de Tucuman, Argentina; Dr. Miguel Hominal, Centro de Investigaciones Clinicas del Litoral, Santa Fe, Argentina; Dr. Mucio Oliveira Jr., Unidade de Hipertensao do INCOR, São Paulo, Brazil; Dr. Luiz Bodanese, Hospital São Lucas da PUCRS, Porto Alegre, Brazil; Dr. Oswaldo Greco, Instituto de Molestias Cardiovasculares, Sao Jose do Rio Preto, Brazil; Dr. Salvador Rassi, Hospital das Clinicas da Universidade Federal de Goiás, Goiania, Brazil; Dr. Nadia Gianetti, Royal Victoria Hospital, Montreal, Canada; Dr. Milan Gupta, Brampton Research, Brampton, Canada; Dr. Thao Huynh, Montreal General Hospital, Montreal, Canada; Dr. Frank Edelmann, Universitätskliniken Göttingen, Göttingen, Germany; Dr. P. Naveen Reddy, Mediciti Hospitals, Hyderabad, India; Dr. J.B. Gupta, S R Kalla Memorial Gastro \& General Hospital, Jaipur, India; Dr. Mukesh Kumar Sarna, Monilek Hospital \& Research Centre, Jaipur, India; Dr. Padma Kumar, Kasturba Medical College and Hospital, Manipal, India; Dr. Prashant Jagtap, Wockhardt Heart Hospital, Nagpur, India; Dr. Aziz Khan, Crescent Hospital \& Heart Centre, Nagpur, India; Dr. Srinivasa Rao, Osmania Medical College \& Hospital, Hyderabad, India; Dr. Maddury Rao, CARE Hospital, Hyderabad, India; Dr. Mukund Kumbla, Omega Hospital, Mangalore, India; Dr. Esio Ronchi, Az.Ospedaliera della Prov.di Pavia Ospedale C. Mira, Casorate Primo, Italy; Dr. Daniele Bertoli, Stab. Osp. San Bartolomeo -Presidio Unico del Levante Ligure, Sarzana, Italy; Dr. Lucio Mos, P.O.Ospedale Civile S.Antonio ASS 4 Medio Friuli, San Daniele Del Friuli, Italy; Dr. Mario Sprovieri, A.O. di Cosenza-Pres.Osped.Ospedale Civile dell'Annunziata , Cosenza, Italy; Dr. Michele Senni, Azienda Ospedaliera-Ospedali Riuniti di Bergamo, Bergamo, Italy; Dr. Alberto Schizzarotto, A.O.S.Antonio Abate Gallarate Pres.Osp.A.Bellini di Somma L , Somma Lombardo, Italy; Prof. dr. A.A. Voors, Universitair Medisch Centrum Groningen, Groningen, Netherlands; Dr. Timo Lenderink, Atrium Heerlen, Heerlen, Netherlands; Dr. F. Den Hartog, Ziekenhuis De Gelderse Vallei , Ede, Netherlands; Dr. Anho H. Liem, Admiraal de Ruyter Ziekenhuis, Goes, Netherlands; Dr. G. Tjeerdsma, Tjongerschans Ziekenhuis, Heerenveen, Netherlands; Dr. Y. Pinto, Academisch Medisch Centrum Universiteit van Amsterdam, Amsterdam, Netherlands; Dr. A. Derks, Streekziekenhuis Midden Twente, Hengelo, Netherlands; Prof. Piotr Ponikowski, 4 Wojskowy Szpital Kliniczny, Wroclaw, Poland; Dr. Magdalena Makowiecka-Ciesla, Gabinet Lekarski CORMED, Warszawa/Anin, Poland; Dr. Calin Florin Pop, Spitalul Judetean de Urgenta Dr. Constantin Opris, Baia Mare, Romania; Dr. Constantin Militaru, Cardiomed srl, Craiova, Romania; Dr. Gabriela Stanciulescu, Spitalul Judetean de Urgenta Pitesti, Pitesti, Romania; Prof. Alexandra Konrady, Institute of Cardiology and Endocrinol.n.a.after Almazov, Saint-Petersburg, Russia; Prof. Sergey Shoustov, Military Medical Academy n.a.S.M Kirov, Saint-Petersburg, Russia; Prof. Vladimir Simanenkov, City Hospital \#26, Saint-Petersburg, Russia; Prof. Zhanna Kobalava, Clinical Hospital \#64, Moscow, Russia; Prof. Sergey Boitsov, Russian Cardiological Scientific and Industrial Complex, Moscow, Russia; Dr. Carolyn Lam, National University Hospital, Singapore, Singapore; Dr. Zee Pin Ding, National Heart Centre, Singapore, Singapore; Dr. Jose Ramon Gonzalez Juanatey, 
Hospital Clinico Universitario Santiago de Compostela, Santiago de Compostela, Spain; Dr. Luis de Teresa Parreño, Clinica Mediterranea de Neurociencias, Alicante, Spain; Dr. Juan Garcia Puig, Hospital La Paz, Madrid, Spain; Dr. David Chivite, Ciutat Sanitaria i Universitaria de Bellvitge, Hospitalet de Llobregat, Cataluña, Spain; Dr. Carlos Calvo, Hospital Clinico Universitario Santiago de Compostela, Santiago de Compostela, Galicia, Spain; Dr. Luis Manzano, Hospital Ramon Y Cajal, Madrid, Spain; Dr. Gonzalo Peña, Hospital San Rafael, A Coruña, Spain; Dr. Mayank Modi, Berks Cardiologists, Wyomissing, PA, United States; Dr. Wayne Leimbach, Oklahoma Heart Institute, Tulsa, OK, United States; Dr. Philip Adamson, Oklahoma Cardiovascular Research Group, Oklahoma City, OK, United States; Dr. Steven Promisloff, Hillsboro Cardiology, Hillsboro, OR, United States; Dr. Steven Krueger, Integrated Cardiology Group, LLC Bryan LGH Heart Inst, Lincoln, NE, United States; Dr. Baxter Montgomery, HCA Research, Houston, TX, United States; Dr. David Colan, Internal Medical Associates of Grand Island, Grand Island, NE, United States 